\section{BMJ Paediatrics Open}

\title{
Incidence of infantile Pompe disease in the Maroon population of French Guiana
}

Narcisse Elenga, ${ }^{1}$ Alain Verloes, ${ }^{2}$ Yajaira Mrsic, ${ }^{1}$ Célia Basurko, ${ }^{3}$ Roxane Schaub, ${ }^{3}$ Emma Cuadro-Alvarez, ${ }^{1}$ Rémi Kom-Tchameni, ${ }^{1}$ Gabriel Carles, ${ }^{4}$ Véronique Lambert, ${ }^{4}$ Rachida Boukhari, ${ }^{5}$ Aniza Fahrasmane, ${ }^{3}$ Anne Jolivet, ${ }^{6}$ Mathieu Nacher, ${ }^{3}$ Jean-François Benoist ${ }^{7}$

To cite: Elenga N, Verloes A, Mrsic $Y$, et al. Incidence of infantile Pompe disease in the Maroon population of French Guiana. BMJ Paediatrics Open 2018;2:e000182. doi:10.1136/ bmjpo-2017-000182

Received 19 July 2017 Revised 16 November 2017 Accepted 4 December 2017

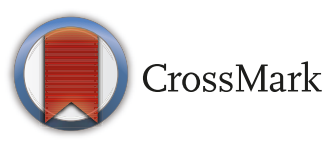

1Department of Pediatrics, Andrée Rosemon Regional Hospital, Cayenne, French Guiana

${ }^{2}$ Department of Genetics, USCP University and INSERM UMR 1141, APHP-Robert Debré University Hospital, Paris, French ${ }^{3}$ Centre d'Investigation Clinique Antilles-Guyane, Inserm 1424, Andrée Rosemon Regional Hospital, Cayenne, French Guiana

${ }^{4}$ Department of Gynecology and Obstetrics, Frank Joly West Guiana Regional Hospital, SaintLaurent-du-Maroni, French Guiana

${ }^{5}$ Deparment of Clinical Biology, Frank Joly West Guiana Regional Hospital, Saint-Laurent-duMaroni, French Guiana ${ }^{6}$ Department of Public Health, Frank Joly West Guiana Regional Hospital, Saint-Laurent-duMaroni, French Guiana ${ }^{7}$ Department of Biochemistry, APHP-Robert Debré University Hospital, Paris, France

Correspondence to Dr Narcisse Elenga; elengafr@ yahoo.fr

\section{ABSTRACT}

Objectives The aim of this study was to describe the epidemiology of infantile Pompe disease (IPD) in French Guiana, a French overseas territory, by combining a retrospective case records study and a prospective anonymous genotyping in a sample of mothers followed in the two major maternity units of French Guiana.

Methods We identified 19 newborns with IPD born within a 13-year-period in French Guiana, corresponding to $1 / 4528$ births. All children were born within the AfricanAmerican Maroon (Bushinengue) community originating from slaves who settled along the Maroni river in the 19th century. We also performed an anonymised screening for all women in postpartum, in the two main maternity units of French Guiana.

Results Genetic investigations revealed that all patients with IPD were homozygotes or compound heterozygotes for two known pathogenic variations: c.2560C>Tp. $($ Arg854*) that has already been reported in AfricanAmericans and c.1942G>A p.(Gly648Ser), a rare previously considered to be variant. We identified no heterozygotes among 453 mothers of various ethnicities in Cayenne, but 15 heterozygotes among 425 mothers (1/27) in SaintLaurent-du-Maroni (95\% Cl 1/45 to 1/17), all from the Maroon community, which corresponds to an expected IPD incidence in Maroons of $1 / 1727$ (95\% $\mathrm{Cl} 1 / 1156$ to 1/8100).

Conclusion The incidence of IPD in the Maroon community is roughly 50 times higher than elsewhere in the world. The presence of only two different variants in all affected patients is compatible with a double founder effect in a relatively small population that has seldom mixed with other regional populations in the past and therefore has a reduced pool of genotypes.

\section{BACKGROUND}

Pompe disease also known as glycogen storage disease type II (0MIM 232300 ) or acid maltase deficiency is an autosomal recessive neuromuscular metabolic disorder caused by an accumulation of glycogen in the lysosome secondary to a deficiency of the lysosomal acid alpha-glucosidase enzyme. ${ }^{12}$ The accumulation of lysosomal glycogen in the cardiac

\section{What is already known on this topic?}

The worldwide incidence of infantile Pompe disease is about 1/150 000 births, except in Taiwan, where its incidence is estimated around $1 / 15000$. Since 1999, patients can benefit from enzyme replacement therapy. The effectiveness of this enzyme replacement therapy for infantile Pompe disease is related to early introduction, before the appearance of clinical signs of heart failure.

\section{What this study adds?}

Infantile Pompe disease in French Guiana shows a much higher incidence than elsewhere in the world. In the Maroon population living along the Maroni river, its incidence appears close to $1 / 2000$ births. These data reveal the existence of a hotspot for infantile Pompe disease and should be of great value for identifying couples at risk.

and skeletal muscles causes progressive cardiomyopathy, generalised muscle weakness and hypotonia. Pompe disease manifests as a clinical spectrum that mainly depends on the residual activity of acid maltase, in which in infantile, atypical infantile, juvenile and adult forms are recognised, based on the age at onset, the rate of disease progression and the profile of organ involvement. The infantile form of Pompe disease (IPD) is a rapidly progressive disease characterised by prominent cardiomegaly, hepatomegaly, weakness and hypotonia, presenting at birth or during the first year of life. In typical IPD, death occurs before 1 year. It occurs later in infancy in atypical IPD. ${ }^{3-5}$ Patients with IPD may have prenatal manifestation detectable by ultrasound scan. The incidence of IPD is around 1/138 000 births in most countries but Taiwan, where its incidence is around 
$1 / 15000 .{ }^{6}$ Since 1999 , patients can benefit from enzyme replacement therapy (ERT). ${ }^{7-12}$

French Guiana is an overseas department and region of France (capital town: Cayenne), situated on the northeastern coast of South America. French Guiana is bounded by the Amapa state of Brazil to the south and east and the Atlantic Ocean to the north east. The Maroni River forms the French Guiana-Suriname border in the west. French Guiana counts about 250000 inhabitants and 6400 births per year. The population is composed of people of mixed African and French ancestry (Creoles), with minorities of metropolitan French, Brazilians, Surinamese, Haitians and other Caribbeans, Chinese and Laotians and the Maroon community. Maroons (or Bushinengue) are descendent from African slaves who escaped (marooned) from the plantations of the current Suriname, a Dutch colony at the time of the slave trade and who banded together and build their own settlements. By 1740, the Maroons challenged the Dutch colonists, forcing them to sign peace treaties. The practice known as 'runaways' is the cultural founding principle of Maroons, which now represents 10\%-20\% of the population in French Guiana and thus constitute a major component of the settlement history of this territory. Most Maroons live along the Maroni river and its branches, in several small towns (Grand-Santi, Maripasoula and so on) and in Saint-Laurent-du-Maroni, the second city of French Guiana. The community counts more than 25000 members in French Guiana and a larger group in Suriname. Maroons are divided into several ethnolinguistic groups: Saramaka, Paramaka, Ndyuka (Aukan), Kwinti, Aluku (Boni) and Matawai. Despite intense cultural exchanges between Maroons, native South Americans and Europeans, there was a low biological mixing of these populations and a unique conservation of genetic heritage. ${ }^{13}$

\section{MATERIAL AND METHODS}

\section{Identification of patients with Pompe disease}

Using multiple sources (hospital records, prenatal diagnosis records and records from the metropolitan diagnostic laboratories), we compiled all patients with IPD diagnosed on an enzymatic basis, from January 2002 to December 2015 (13 years). Genotype was available for eight children born after 2010. In the same period, no patient was identified with later-onset Pompe disease.

\section{Heterozygote screening}

From May 2014 to July 2015, an anonymised screening was performed in the two main maternity units of French Guiana (Cayenne and Saint-Laurent-du-Maroni) for the two variants identified in the index patients. Inclusion was proposed to all women in puerperium on a voluntary basis. Patients were included only if they had not had a child with Pompe disease and no sign of cardiac hypertrophy by fetal ultrasonography during the current pregnancy. Oral information was accompanied by a written consent form. Dried blood spot (DBS) on paper filter was collected at the time of a routine blood testing.

\section{Mutation analysis in patients}

In patients with Pompe disease, GAA (NM_000152.4) sequence analyses were performed from genomic DNA obtained from peripheral blood sample by Sanger method using classical routine protocols (data not shown).

\section{Mutation analysis of DBS}

The DNA was extracted from the DBS by hydroxide sodium. ${ }^{14}$ The two variants previously identified in the patient group were screened on maternal samples. After specific amplification of exons 14 and 18, c.1942G $>$ A (p.Gly648Ser) and c.2560C $>$ T (p. Arg854*) mutations were analysed by mutation-specific restriction enzyme digestion using PstI and Bsu36I enzymes, respectively.

\section{RESULTS}

\section{Infantile Pompe disease}

Using multiple sources, we ascertained 19 patients born in a 13-year period (January 2002-December 2015) with Pompe disease. All patients were affected by the infantile form. They all had Maroon parents (based on linguistic criteria) and were born in Saint-Laurent-du-Maroni. Most patients were identified in infancy following respiratory distress, the first sign of cardiac failure due to cardiomyopathy. Hypotonia of variable severity was associated. The first 14 patients in our series died in infancy. The last five affected patients were transferred to Robert Debré University Hospital within 2 weeks after enzymatic confirmation to initiate treatment. Five patients benefitted from ERT since 2012. One died at 2 years of age of sepsis. The four other are alive after 36, 26, 24 and 5 months of treatment, respectively.

According to the birth statistics from the French National Institute for Statistics and Economics Studies, ${ }^{15}$ the total number of births in French Guiana between 2002 to 2015 was 86040 (mean: 6219/year). For SaintLaurent-du-Maroni, the mean annual birth number was 2344. Hence, the annual incidence of IPD was $1 / 4528$ birth for whole territory and $1 / 1727$ birth for Saint-Laurent-du-Maroni maternity.

The last 10 patients were genotyped (table 1). Only two variants were identified: c.1942G $>$ Ap.(Gly648Ser) and c. $2560 \mathrm{C}>\mathrm{Tp}$. $\left(\operatorname{Arg} 854^{*}\right)$. One patient was homozygous for p.Arg854*. All others were compound heterozygotes (table 1). We did not identify homozygotes for p.Gly648Ser. The cross-reactive immunological material (CRIM) status was positive in the four compound heterozygotes that were specifically tested before initiation of ERT and negative in the patient homozygous for the c. $2560 \mathrm{C}>\mathrm{T}$ mutation, as previously reported. 
Table 1 Characteristics and genotype of patients with Pompe disease

\begin{tabular}{|c|c|c|c|c|c|c|c|}
\hline Patient & Genotype & ERT & Outcome & Year of birth & Clinical phenotype & CRIM status & Sibship \\
\hline 1 & p.(Gly648Ser); (Arg854*) & Y & Alive & 2015 & Infantile & Positive & \\
\hline 2 & p.(Gly648Ser); (Arg854*) & $\mathrm{Y}$ & Alive & 2013 & Infantile & Positive & \\
\hline 3 & p.(Gly648Ser); (Arg854*) & $\mathrm{Y}$ & Alive & 2013 & Infantile & Positive & \\
\hline 4 & p.(Gly648Ser); (Arg854*) & $\mathrm{Y}$ & Alive & 2012 & Infantile & Positive & Sister 9/F1 \\
\hline 5 & p.(Gly648Ser); (Arg854*) & $\mathrm{N}$ & Dead & 2011 & Infantile & Positive & \\
\hline 6 & p.(Gly648Ser); (Arg854*) & $\mathrm{N}$ & Dead & 2011 & Infantile & Positive & \\
\hline 7 & p.(Gly648Ser); (Arg854*) & Y & Dead & 2010 & Infantile & Positive & Brother 17/F2 \\
\hline 8 & p.(Gly648Ser); (Arg854*) & $\mathrm{N}$ & Dead & 2010 & Infantile & ND & \\
\hline 9 & ND & $\mathrm{N}$ & Dead & 2010 & Infantile & ND & Brother 4/F1 \\
\hline 10 & p.(Gly648Ser); (Arg854*) & $\mathrm{N}$ & Dead & 2008 & Infantile & ND & \\
\hline 11 & ND & $\mathrm{N}$ & Dead & 2007 & Infantile & ND & Brother 19/F3 \\
\hline 12 & p. $\left(\operatorname{Arg} 854^{\star}\right) ;\left(\operatorname{Arg} 854^{\star}\right)$ & $\mathrm{N}$ & Dead & 2006 & Infantile & Negative & \\
\hline 13 & p. $\left(\operatorname{Arg} 854^{*}\right) ;((?))$ & $\mathrm{N}$ & Dead & 2005 & Infantile & $\mathrm{N}$ & Brother 15/F4 \\
\hline 14 & ND & $\mathrm{N}$ & Dead & 2005 & Infantile & $\mathrm{N}$ & \\
\hline 15 & ND & $\mathrm{N}$ & Dead & 2003 & Infantile & ND & Sister 13/F4 \\
\hline 16 & ND & $\mathrm{N}$ & Dead & 2003 & Infantile & ND & \\
\hline 17 & ND & $\mathrm{N}$ & Dead & 2002 & Infantile & ND & Brother 7/F2 \\
\hline 18 & ND & $\mathrm{N}$ & Dead & 2002 & Infantile & $\mathrm{N}$ & Cousin 19/F3 \\
\hline 19 & p.(Gly648Ser); ((?)) & $\mathrm{N}$ & Dead & 2002 & Infantile & ND & Cousin 18/F3 \\
\hline
\end{tabular}

CRIM, cross-reactive immunological material; ERT, enzyme replacement therapy; F, the family to which the child belongs; N, no; ND, not done; Y, yes.

\section{Heterozygote screening}

Screening was performed among 453 women of various ethnicities in Cayenne and 425 women, most from the Maroon community, in Saint-Laurent-du-Maroni. No heterozygote was identified in Cayenne, but 15 heterozygotes (nine Gly648Ser and six p.Arg854*) were identified in Saint-Laurent-du-Maroni (1/27) $(95 \%$ CI $1 / 45$ to $1 / 17$ ), all from the Djuka and Boni ethnolinguistic subgroups of the Maroon community (table 2). Using Hardy-Weinberg equilibrium, we computed an expected prevalence of Pompe disease in this community of $1 / 2916$ (95\% CI $1 / 1156$ to $1 / 8100)$.

\section{DISCUSSION}

IPD in French Guiana shows a much higher incidence than elsewhere in the world, particularly in Western

Table 2 Heterozygote mothers' screening by maternity

\begin{tabular}{lccc}
\hline Maternity & Cayenne & SLM & Total \\
\hline Number of inclusions & 453 & 425 & 878 \\
\hline Heterozygote & 0 & 15 & 15 \\
$\begin{array}{l}\text { Mutation c.1942G>A } \\
\text { (p.Gly648Ser) }\end{array}$ & 0 & 9 & 9 \\
$\begin{array}{l}\text { Mutation c.2560C >T } \\
\text { (p.ARG854*) }\end{array}$ & 0 & 6 & 6 \\
\hline
\end{tabular}

SLM, Saint-Laurent-du-Maroni.
Europe. In the Maroon population living along the lower Maroni river, its incidence appears close to 1/2000 births (ie, more than one case per year for the regional maternity that currently has about 2500 birth/year) and stable over time: 1 or 2 IPD/year since 2002. Indeed, the real incidence of IPD may be underestimated: a large part of the Maroon community lives in remote parts along the Maroni river, far from hospitals or clinics (noteworthy in Suriname) and some children born in Saint-Laurent-du-Maroni may have died undiagnosed or misdiagnosed.

The mutational spectrum appears limited to two variants. p.Arg854* is a variant originated from North Africa. It spread to the south along the east coast of Africa and was imported to Americas by the slave trade. ${ }^{16-18}$ In cDNA studies, the allele carrying this mutation is not expressed. ${ }^{19}$ Patients homozygous for p.Arg854* have no residual enzyme (negative CRIM status). ${ }^{20-22}$ p.Gly648Ser is a rarer variant already reported in a patient with lateonset Pompe disease, in a compound heterozygous state with another hypomorphic mutation. The directed mutagenesis tests show that this mutation is responsible for an almost complete loss of activity. ${ }^{23}$

Distant familial relationships were identified between several patients, but no child was born from an overt consanguineous union between cousins or closer, as these unions are not culturally accepted in the Maroon population. The simplest explanation for this high incidence is a double founder effect maintained by endogamy 
among Maroon groups who were largely isolated from the rest of the world for geographical reasons (along the Maroni river, most villages are only accessible by airplane or pirogue) and, in the past, not mixed with the other French Guianese populations for cultural or linguistic reasons. Surprisingly, most patients were compound heterozygotes. The phenotype of p.Gly648Ser homozygotes has not been reported and, indeed, is unpredictable but could be mild. Nevertheless, to the best of our knowledge, no late-onset Pompe disease has been identified in the Guianese population: enzymatic diagnosis of Pompe disease is only performed by a few number of laboratories in France, and we confirmed with them that no samples of patients issuing from the region has an enzymatic diagnosis of juvenile or adult form since 2000 and that no patient was diagnosed in France with a homozygous p.Gly648Ser genotype.

In this study, we have indeed shown the practical feasibility of an enzymatic neonatal screening of Pompe disease on dried blood, followed by genotyping of samples showing low enzymatic activity. Implementation of a systematic neonatal screening in French Guiana would nevertheless require political decisions at the level of the French health authorities, which are beyond the scope of this study.

The availability of ERT for IPD, for which effectiveness is clearly related to early treatment, before the appearance of clinical signs of heart failure, ${ }^{24-26}$ could justify routine prenatal screening for all Guianese infants or those from Maroon ethnicity. Indeed, all infants with IPD infants born in French Guiana since 2011 have been offered ERT. Such screening is already done in Taiwan and in some US states. Another approach would be to implement neonatal screening, which currently exists in Taiwan and is announced in some US states.

A second aim of the study was to check feasibility of carrier screening for IPD by simple targeted genotyping of the two prevalent mutations to reduce the burden of IPD in this population. We indeed showed carrier prevalence similar to the prevalence of cystic fibrosis or spinal muscular atrophy (SMA) in the European population. If made available to the Guianese population, carrier screening would identify a number of couples at risk and could allow delivering appropriate genetic counselling and an access to prenatal diagnosis.

Our study has some limitations. Most cases prior to 2010 were identified retrospectively and had no molecular diagnosis to confirm disease. The carrier screening indeed showed a high prevalence of heterozygotes, but we cannot exclude that the choice to be screened was not supported by an uncovered family history.

\section{CONCLUSIONS}

The incidence of IPD in the Maroon community is roughly 50-100 times higher than reported elsewhere in the world and particularly in mainland France. The presence of only two different mutations among all genotyped cases confirms a double founder effect in a relatively small population that has seldom mixed with the other regional populations in the past and therefore has a reduced pool of genotypes. Implementation of a carrier screening in French Guiana would allow identification of at risk couples, appropriate genetic counselling and access to prenatal diagnosis, whereas neonatal screening would permit presymptomatic access to ERT.

Acknowledgements The authors would like to thank Balthazar Ntab of the Department of Medical Information, Saint-Laurent-du-Maroni Hospital, Catherine Caillaud of the Department of Biochemistry, Necker-Enfants-Malades Hospital, Paris, Roseline Froissart of the Department of Biochemistry, University Hospital, Lyon, and Hélène Ogier de Baulny of the Department of Metabolic Disorders, Robert Debré University Hospital, Paris, for data collection.

Contributors NE, AV and MN analysed the data and drafted the manuscript; YM, EC-A, RK-T, GC, VL and RB collected the data; and CB and AF provided necessary logistic support. J-FB contributed in data production. RS, AJ and J-FB provided critical comments on the manuscript.

Funding This work was supported by the European Regional Development Fund (ERDF), grant $\mathrm{N}^{\circ} 1990 /$ sgar-de/2013.

Competing interests None declared.

Patient consent Parental/guardian consent obtained.

Ethics approval Ethical Research Committee of INSERM ( $\left.{ }^{\circ} 14-131\right)$ and by the Commission Nationale Informatique et Libertés (N/Réf: MMS/CWR/AR 153222).

Provenance and peer review Not commissioned; externally peer reviewed.

Data sharing statement No additional data are available.

Open Access This is an Open Access article distributed in accordance with the Creative Commons Attribution Non Commercial (CC BY-NC 4.0) license, which permits others to distribute, remix, adapt, build upon this work non-commercially, and license their derivative works on different terms, provided the original work is properly cited and the use is non-commercial. See: http://creativecommons.org/ licenses/by-nc/4.0/

C Article author(s) (or their employer(s) unless otherwise stated in the text of the article) 2018. All rights reserved. No commercial use is permitted unless otherwise expressly granted.

\section{REFERENCES}

1. Pompe JC. Over idiopatischehypertrophie van her hart. Ned Tijdshr Geneeskd 1932;76:304.

2. Hirshhorn RRA. Glycogen storage disease type II: acid alphaglucosidase (acid maltase) deficiency. In: Scriver C, Sly W, Childs B, Beaudet A, Valle D, et al. eds. The metabolic and molecular basis of inherited disease. 8th edn: McGraw-Hill Medical, 2001:389-420.

3. Kishnani PS, Nicolino M, Voit T, et al. Chinese hamster ovary cellderived recombinant human acid alpha-glucosidase in infantileonset Pompe disease. J Pediatr 2006;149:89-97.

4. van den Hout HM, Hop W, van Diggelen OP, et al. The natural course of infantile Pompe's disease: 20 original cases compared with 133 cases from the literature. Pediatrics 2003;112:332-40.

5. Byrne BJ, Kishnani PS, Case LE, et al. Pompe disease: design, methodology, and early findings from the Pompe Registry. Mol Genet Metab 2011;103:1-11.

6. Chien $\mathrm{YH}$, Chiang SC, Zhang XK, et al. Early detection of Pompe disease by newborn screening is feasible: results from the Taiwan screening program. Pediatrics 2008;122:e39-45.

7. Van den Hout H, Reuser AJ, Vulto AG, et al. Recombinant human alpha-glucosidase from rabbit milk in Pompe patients. Lancet 2000;356:397-8

8. Kishnani PS, Hwu WL, Mandel H, et al. A retrospective, multinational, multicenter study on the natural history of infantileonset Pompe disease. J Pediatr 2006;148:671-6.

9. Kishnani PS, Corzo D, Leslie ND, et al. Early treatment with alglucosidase alpha prolongs long-term survival of infants with Pompe disease. Pediatr Res 2009;66:329-35.

10. Kishnani PS, Corzo D, Nicolino M, et al. Recombinant human acid [alpha]-glucosidase: major clinical benefits in infantile-onset Pompe disease. Neurology 2007;68:99-109. 
11. Chakrapani A, Vellodi A, Robinson P, et al. Treatment of infantile pompe disease with alglucosidase alpha: the UK experience. $J$ Inherit Metab Dis 2010;33:747-50.

12. Angelini C, Semplicini C. Enzyme replacement therapy for Pompe disease. Curr Neurol Neurosci Rep 2012;12:70-5.

13. Brucato N, Cassar O, Tonasso L, et al. The imprint of the Slave Trade in an African American population: mitochondrial DNA, $Y$ chromosome and HTLV-1 analysis in the Noir Marron of French Guiana. BMC Evol Biol 2010;10:314.

14. Zhou H, Hickford JG, Fang Q. A two-step procedure for extracting genomic DNA from dried blood spots on filter paper for polymerase chain reaction amplification. Anal Biochem 2006;354:159-61.

15. INSEE. https://www.insee.fr/fr/statistiques/2559184

16. Becker JA, Vlach J, Raben N, et al. The African origin of the common mutation in African American patients with glycogen-storage disease type II. Am J Hum Genet 1998;62:991-4.

17. Adams EM, Becker JA, Griffith L, et al. Glycogenosis type II: a juvenile-specific mutation with an unusual splicing pattern and a shared mutation in African Americans. Hum Mutat 1997;10:128-34.

18. Oba-Shinjo SM, da Silva R, Andrade FG, et al. Pompe disease in a Brazilian series: clinical and molecular analyses with identification of nine new mutations. J Neurol 2009;256:1881-90.

19. Niño MY, Mateus HE, Fonseca DJ, et al. Identification and functional characterization of gaa mutations in colombian patients affected by pompe disease. JIMD Rep 2013;7:39-48.
20. Messinger YH, Mendelsohn NJ, Rhead W, et al. Successful immune tolerance induction to enzyme replacement therapy in CRIM-negative infantile pompe disease. Genet Med 2012;14:135-42.

21. Berrier KL, Kazi ZB, Prater SN, et al. CRIM-negative infantile pompe disease: characterization of immune responses in patients treated with ERT monotherapy. Genet Med 2015;17:912-8.

22. Bali DS, Goldstein JL, Rehder C, et al. Clinical laboratory experience of blood CRIM testing in infantile pompe disease. Mol Genet Metab Rep 2015;5:76-9.

23. Huie ML, Tsujino S, Sklower Brooks S, et al. Glycogen storage disease type Il: identification of four novel missense mutations (D645N, G648S, R672W, R672Q) and two insertions/deletions in the acid alpha-glucosidase locus of patients of differing phenotype. Biochem Biophys Res Commun 1998;244:921-7.

24. Kemper AR, Hwu WL, Lloyd-Puryear M, et al. Newborn screening for pompe disease: synthesis of the evidence and development of screening recommendations. Pediatrics 2007:120:e1327-34.

25. Chien $\mathrm{YH}$, Lee NC, Huang HJ, et al. Later-onset pompe disease: early detection and early treatment initiation enabled by newborn screening. J Pediatr 2011;158:1023-7. e1.

26. Chien YH, Lee NC, Thurberg BL, et al. Pompe disease in infants: improving the prognosis by newborn screening and early treatment. Pediatrics 2009;124:e1116-25. 